\title{
Influence of Water-Structure and Soil-Structure Interaction on Seismic Performance of Sea-Crossing Continuous Girder Bridge
}

\author{
Jie Guo, ${ }^{1,2}$ Kunpeng Wang $\left(\mathbb{D},{ }^{3}\right.$ Hongtao Liu, ${ }^{4}$ and Nan Zhang $\mathbb{D}^{1}$ \\ ${ }^{1}$ School of Civil Engineering, Beijing Jiaotong University, Beijing 100044, China \\ ${ }^{2}$ China Railway 14th Bureau Group Co. LTD., Jinan 250101, China \\ ${ }^{3}$ CCCC Highway Bridges National Engineering Research Centre Co., Ltd., Beijing 100120, China \\ ${ }^{4}$ Beijing University of Civil Engineering and Architecture, Beijing 102612, China \\ Correspondence should be addressed to Nan Zhang; nzhang@bjtu.edu.cn
}

Received 11 October 2021; Revised 27 October 2021; Accepted 11 November 2021; Published 7 December 2021

Academic Editor: Qian Chen

Copyright ( 2021 Jie Guo et al. This is an open access article distributed under the Creative Commons Attribution License, which permits unrestricted use, distribution, and reproduction in any medium, provided the original work is properly cited.

\begin{abstract}
Based on the Hong Kong-Zhuhai-Macao project, considering the fluid-structure interaction and soil-structure interaction, the seismic response of a sea-crossing continuous girder bridge is analyzed. Three-dimensional nonlinear numerical bridge model is developed, in which the hydrodynamic force is represented by added mass and pile-soil interaction is represented by $p-y$ elements. Meanwhile, stratification of soil is considered in the free field analysis. Through the comparison of responses of the bridge cases, the effects of earthquake-induced hydrodynamic force and pile-soil interaction are studied. For the influence of hydrodynamic force, the results show that it is relatively slight as compared with pile-soil interaction; moreover pile foundation is more sensitive to it than other bridge components. The influence of pile-soil interaction is relatively significant. When both of the interactions are considered, the influence is not a simple superposition of acting alone, so it is recommended to consider both factors in dynamic analysis.
\end{abstract}

\section{Introduction}

With the development of economy and the necessity of coastal regional linkages, a certain number of seacrossing bridges have been constructed around the world in the last few decades. Earthquake risk is usually very high in coastal areas, due to movement and collisions between continental and oceanic plate margins [1]. Earthquake brings great challenge to the safety of bridge structure [2]. In addition, compared with the bridge on land, the sea-crossing bridge is always in deep water. The complex environment of the sea-crossing bridge also means that the seismic response and design of the bridge are quite different from those of the conventional bridge [3]. However, most previous studies focused on the seismic response of bridges constructed on onshore sites $[4,5]$; a comprehensive study on the seismic response of sea-crossing continuous girder bridge is rarely reported in the literature.
In the seismic analyses and design of bridge, how to consider pile-soil interaction is always involved [6]. Currently, the following two methods are mostly adopted in the seismic design [7]. One is connecting the foundation and the soil with a simple spring; another is more simply assuming that the foundation and the soil are consolidated. All the above assumptions ignore dynamic soil-structure interaction (SSI) [8], and a large number of seismic disaster data show that this assumption is unreasonable $[9,10]$. In addition, Makris et al. [11] analyzed the response of the Painter Street Bridge located in California, and results showed the significance of reasonable consideration of the pile-soil interaction. Hutchinson et al. [12] studied the seismic response of viaduct structure supported by expanded bored pile considering soil-pile interaction. Soneji and Jangid [13] studied the influence of soil-structure interaction on seismic performance of seismic-isolated cable-stayed bridge. The results showed that the soil had a significant impact on the dynamic response of bridge, and ignoring the pile-soil 
interaction effect might underestimate the displacement of the bridge. Using the improved Penzien model to simulate the soil-structure interaction, Chen et al. [14] set up bridge models of high-speed railway of multispan simply supported. The seismic responses of the models show that the influence of the SSI on seismic responses of the bridge cannot be ignored.

There is also a need for special consideration of interaction between the submerged structure and fluid under seismic excitation. The dynamic force is called earthquakeinduced hydrodynamic force [15]. The study of the hydrodynamic force started from the dam-water interaction [16]. With the continuous development of deep-water bridges, researchers began to pay attention to the hydrodynamic force on cylinders [17]. The interaction force is related to the structures, fluid, ground motions, and boundary conditions, so accurate hydrodynamic force can be obtained by fluid-structure coupling analysis [18]. However, the calculation cost is too high, which is not suitable for engineering. The simplified hydrodynamic calculation method based on the radiation wave theory proposed by Liaw and Chopra [19] can meet the requirements and accuracy of engineering [20]. According to the radiation wave theory, when considering the compressibility of water, earthquake-induced hydrodynamic force is a frequency dependent function. Du et al. [21] proposed an accurate and efficient time-domain model to transform while many researchers find that water compressibility can be ignored in problems for relatively flexible and slender structures such as bridge piers and piles [19, 22]. Later, Li and Yang [23], Jiang et al. [24], and Wang et al. [25] studied the fitting calculation formulas for circular cylinders in incompressible and nonviscous fluid based on the radiation wave theory. In bridge engineering, most of the underwater components are columns with noncircular cross sections. Zhao et al. [26] established a simplified formula for the hydrodynamic force of rectangular column by curve fitting numerical solution. Huang and Li [27] studied the influence of water on the dynamic response of bridge pier. Based on the above researches, the influences of pile-soil and water-structure interaction on deep-water continuous rigid frame bridge in reservoir area was analyzed by $\mathrm{Wu}$ et al. [28].

However, there still lack of research which discusses the effect of water-structure and pile-structure interaction on the dynamic response of actual sea-crossing engineering projects, especially for the most commonly and widely used continuous girder bridge [29]. Therefore, in this paper, on the foundation of previous researchers, based on the Hong Kong-Zhuhai-Macao bridge engineering, the influences of the water-structure interaction and pile-structure interaction on the response of multispan continuous girder bridge are examined.

\section{Seismic Analysis Methodology}

2.1. Hydrodynamic Force. For slender columns such as bridge piers, it is reasonable that compressibility and viscosity of water and the free surface waves can be neglected when calculating the earthquake-induced hydrodynamic force. Thus, based on the radiation hydrodynamic theory, the water-cylinder interaction force can be expressed as product of an added mass of water and the acceleration of the cylinder. Namely, when considering water-structure interaction, the dynamic equation of the structure is expressed as

$$
\left[M_{s}+M_{w}\right]\left\{\ddot{u}_{s}\right\}+\left[C_{s}\right]\left\{\dot{u}_{s}\right\}+\left[K_{s}\right]\left\{u_{s}\right\}=-\left[M_{s}+M_{w}\right]\left\{\ddot{u}_{g}\right\},
$$

where $\boldsymbol{M}_{\boldsymbol{s}}$ is the mass matrix of structure; $M_{w}$ is the added mass matrix of hydrodynamic force, as it is related to the elastic deformation of the structure; it is a spatially coupled off-diagonal mass matrix; $\ddot{u}_{s}$ is the acceleration vector of structure; $\boldsymbol{C}_{s}$ is the damping matrix of structure; $\dot{u}_{s}$ is the velocity vector of structure; $\boldsymbol{K}_{s}$ is the stiffness matrix of structure; $\boldsymbol{u}_{s}$ is the displacement vector of structure; and $\ddot{u}_{g}$ is the ground motion acceleration vector.

Due to the off-diagonal of $M_{w}$, there are difficulties in engineering calculation. In the present literature, the precision of the centralized diagonalization method with rigid column assumption meets the engineering requirement [20]. Therefore, this paper adopts the above simplified method to obtain the added mass of interaction.

The cross section of the bridge pier is nearly rectangular. The two sides of the rectangular section are $a$ and $b$, respectively, where $a$ is the length of the side perpendicular to the direction of the ground motion. The simplified formula of the added mass at height $y$ from the bottom of the water can be expressed as [26]

$$
m_{w}=4 \rho a^{2} d_{1}\left[1-\frac{y}{h} e^{d_{2}(y / h-1)}\right],
$$

in which $\rho$ is the density of water; $h$ is the depth of water; $d_{1}$ and $d_{2}$ are fitting coefficients, and the expressions are as follows:

$$
\begin{aligned}
& d_{1}=m_{1}\left(\frac{2 a}{h}\right)^{m_{2}}+0.412\left(\frac{a}{b}\right)^{-1.012}+0.952 \\
& d_{2}=n_{1}\left(\frac{2 a}{h}\right)^{-1.26}+n_{2} . \\
& m_{1}=-0.35\left(\frac{a}{b}\right)^{-1.092}-0.198 \\
& m_{2}=0.766 e^{0.0471 a / b}-0.782 e^{-1.401 a / b} \\
& n_{1}=-0.0157\left(\frac{a}{b}\right)^{2}+0.194 \frac{a}{b}+0.846 \\
& n_{2}=0.004\left(\frac{a}{b}\right)^{2}-0.0533 \frac{a}{b}+2.143 .
\end{aligned}
$$

2.2. Pile-Soil Interaction. Numerical analysis and simplified method are commonly used to analyze pile-soil dynamic interaction [30]. Using $2 \mathrm{D}$ or $3 \mathrm{D}$ continuum numerical simulation tends to be much more computationally consuming and the result is not easy to converge [31]. As this 
paper mainly focuses on the dynamic response of bridge structure, simplified method is adopted to consider the pilesoil interaction. Most simplified models are put forward based on beam on nonlinear Winkler foundation, among which $p-y$ method is the most widely used and has relatively high accuracy [32]. The method of $p-y$ curves generally refers to the general terms including $p-y$ element (simulating the lateral pile-soil action), $t-z$ element (simulating the axial friction), and $q$ - $z$ element (simulating the pile tip resistance).

The formula of $p-y$ curve of the same pile foundation is different for different soils. Here is a brief introduction to formulas for clay and sand, respectively, which are used in this paper. For clay under cyclic loading, the ultimate soil resistance $\left(p_{u}\right)$ per unit length of pile is [33]

$$
p_{u}=\min \left(\begin{array}{c}
\left(3+\frac{r^{\prime}}{c_{u}} x+\frac{J}{D} x\right) c_{u} D \\
9 c_{u} D
\end{array}\right),
$$

where $r^{\prime}$ is the effective weight of soil; $c_{u}$ is the undrained shear strength of soil; $x$ is the depth of pile node; $J$ is a constant and is taken as 0.5 according to recommendation. $D$ is the diameter of pile. The force-displacement curve of $p-y$ element is expressed as

$$
\begin{aligned}
& y \leq 3 y_{50}: \frac{p}{p_{u}}=0.5\left(\frac{y}{y_{50}}\right)^{1 / 3} \\
& \cong 3 y_{50}<y<15 y_{50}: p=0.72 p_{u}\left(\frac{x}{x_{r}}\right) \\
& y>3 y_{50}: \\
& x<x_{r} \\
& \cong y \geq 15 y_{50}: \text { The same constant } \\
& x \geq x_{r}: p=0.72 p_{u}
\end{aligned}
$$

where $y$ is pile deformation; $y_{50}$ is the lateral displacement of pile at half of the ultimate soil resistance, and $y_{50}=2.5 \varepsilon_{50} D$, $\varepsilon_{50}$ is the strain of soil at half of the maximum theoretical stress; $p$ is the soil resistance; $x_{r}$ is the critical depth and defined as [34]

$$
x_{r}=\left(\frac{6 c_{u} D}{\gamma^{\prime} D+J c_{u}}\right),
$$

For the $p-y$ curve of sand under cyclic load, the ultimate soil resistance $\left(p_{u}\right)$ is also determined first. Combining the simple wedge-type failure model and flow-through type failure model, $p_{u}$ is given by

$$
p_{u}=\min \left(\begin{array}{c}
\left(\frac{C_{1}}{D}+C_{2}\right) r^{\prime} x \\
C_{3} r^{\prime} x
\end{array}\right) \text {, }
$$

where $C_{1} C_{2} C_{3}$ are the coefficients that change with the friction angle, and the values are referenced to American Petroleum Institute (API) recommendations [34]; the meanings of the same parameters are as above.

The force-displacement curve of $p-y$ element is expressed as

$$
p=a p_{u} \tanh \left(\frac{k x}{a p_{u}} y\right),
$$

where $a$ is the correction coefficient, with a value of 0.9 ; $k$ is the initial modulus of subgrade reaction.

The $t-z$ curve of clay used in this paper is briefly described as follows. The ultimate friction resistance $\left(f_{\max }\right)$ is

$$
f_{\max }=\alpha_{z} c_{u} \leq 263 k P a .
$$

The force-displacement curve is defined as follows:

$$
\frac{f}{f_{\max }}= \begin{cases}0.593157 * \frac{R}{0.12}, & R \leq 0.12 \\ \frac{\mathrm{R}}{(0.095155+0.892937 * R)}, & R \leq 0.74 \\ 0.978929-0.115817 *(R-0.74), & R \leq 2.0 \\ 0.833, & R>2.0\end{cases}
$$

where $f$ is the soil resistance; $R$ is relative deformation, and $R=100 * / D$, where $z$ is the deformation of pile [35].

The $t-z$ curve of sand is described as follows. The ultimate friction resistance is [32]

$$
f_{\max }=K \sigma_{v}^{\prime} \tan \left(\frac{3}{4} \phi\right),
$$

where $K$ is pressure coefficient of soil; $\sigma_{v}^{\prime}$ is the effective vertical stress of soil; $\phi$ is the friction angle of soil [36].

The force-displacement curve is defined as follows:

$$
f=f_{\max }\left(2 \sqrt{\frac{z}{0.51}}-\frac{z}{0.51}\right) .
$$

The $q-z$ curve of sand at pile top is briefly described as follows. The ultimate resistance is [31] 


$$
\begin{aligned}
& q_{\max }=\frac{1.27}{D} q_{\max }^{\prime} \\
& q_{\max }^{\prime}= \begin{cases}57.5 * N_{S P T} & 0 \leq N_{S P T} \leq 50 \\
2900 & N_{S P T}>50\end{cases}
\end{aligned}
$$

where $N_{S P T}$ is the blow count of standard penetration test (SPT).

The force-displacement curve is defined as follows:

$$
\frac{q}{q_{\max }}=-1.079 \times 10^{-4} \times R^{4}+3.558 \times 10^{-3} \times R^{3}-4.512 \times 10^{-2} \times R^{2}+0.349 \times R
$$

where $q$ is the resistance of soil.

For pile group foundation, when pile spacing is less than eight times the pile diameter, the so-called pile group effect needs to be considered generally [37]. Pile group effect refers to the phenomenon that the bearing capacity of pile group is less than the sum of the capacity of single pile [30]. In this paper, the widely used "p-multiplier" method is applied to consider the pile group effect [38], and the parameter values are determined by referring to the experiment conducted by Brown et al. [39].

\section{Bridge Model and Analysis Cases}

3.1. Prototype and Numerical Model of Bridge. A six-span continuous girder bridge at the nonnavigable spans of the Hong Kong-Zhuhai-Macao link is adopted as the example in this study. Actually, the site conditions, heights of pile foundation, and bridge piers have some differences along the longitudinal direction of the bridge. Here the differences are ignored, and the soil is simplified as layered soil. For the influence of adjacent bridge spans, only the weight of girder is considered. The bridge has six spans of $85 \mathrm{~m}$ each, so the total length is $510 \mathrm{~m}$. The dimensions of the bridge and its main sections are shown in Figure 1. The main girder is arranged in two parts with the cross section of steel-concrete composite box, the steel deck is the Q345qD steel [40], and the concrete is the C60 concrete [41]. The bearing is the lead rubber bearing (LRB). The bridge pier is rectangular hollow with one longitudinal web, the longitudinal reinforcement is HRB335 [42], and the concrete is C50 [41]. The bridge cap is connected with $2 \times 3$ reinforced concrete pile foundation, and the pile is made of C35 concrete [41].

The pier is located in an environment where the normal water level is about $20 \mathrm{~m}$. The site conditions of the soil layers where the pile foundation is located are shown in Figure 2, and the main mechanical parameters of soil are shown in Table 1. The three-dimensional finite element model of the bridge is implemented in the commercial finite element software ABAQUS, as shown in Figure 3. Beam elements are used for main girders, piers, and pile foundations, among which elastoplastic damage model is used for concrete material and elastic model is used for reinforcement. The bearings are simulated by bilinear connection elements. The pile-soil interaction is represented by nonlinear springs based on the $p-y$ method described above.
3.2. Ground Motions and Analysis Cases. According to Figure 2 and Table 1, the average velocity of shear wave in the top $30 \mathrm{~m}$ of soil $\left(v_{s}\right)$ in the bridge construction site is $103 \mathrm{~m} / \mathrm{s}$. Three ground motion records are selected from the PEER Strong Motion Database [42], and $v_{s}$ of the records ranges from $114 \mathrm{~m} / \mathrm{s}$ to $133 \mathrm{~m} / \mathrm{s}$. The three records are the EW component of Chuetsu-oki seismic record measured at MYG017 station in 2007, the $90^{\circ}$ component of Yountville seismic record measured at APEEL 2-Redwood City station in 2000, and the EW component of Niigata seismic record measured at KNG002 station in 2004. Besides, the peak ground accelerations of the above records are uniformly adjusted to $2 \mathrm{~m} / \mathrm{s}^{2}$. The time history of acceleration and the Fourier amplitude spectrum of Chuetsuoki record are shown in Figure 4.

The free ground seismic response of layered soil is obtained by EERA analysis. Here, only the longitudinal bridge response is considered, so the free field response at the corresponding soil depth is input at the free end of the $p-y$ elements.

Four cases are considered in the paper, as shown in Table 2. When pile-soil interaction is not considered, the model is consolidated at the bottom of the piers.

\section{Numerical Results and Discussions}

4.1. Influence of Water-Structure Interaction. By comparing the responses of Case 1 and Case 2 in Table 2, the influence of water-structure interaction which neglects pile-soil interaction is obtained. Figure 5 shows the time history of absolute displacement of pier No. 4 at top under Chuetsu-oki record. It can be found that the hydrodynamic force slightly changes the dynamic response of the structure. The periodic characteristics, the amplitudes, and time of the peak response are all changed. Combining with Table 3 (the fundamental periods and corresponding change rates of bridge under cases), the elongation ratio of hydrodynamic force to the fundamental period is $1.8 \%$.

Figure 6 shows the bending moment envelopes of piers No. 1 and No. 4 under the excitation of Chuetsu-oki records. As can be seen, the responses of bending moment along the whole height are slightly increased by the hydrodynamic force. In order to reflect the influence more intuitively, the discrepancy rate of response is defined as follows. The average value of maximums of the envelopes under the three seismic excitations is denoted as the peak response value 


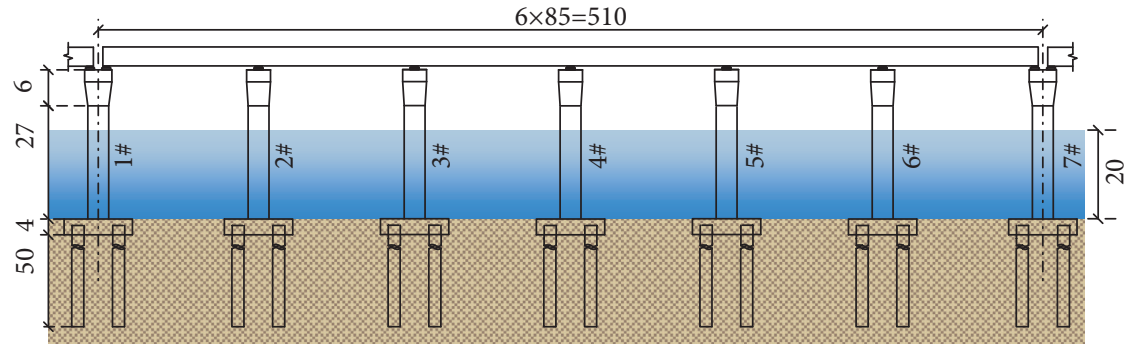

(a)
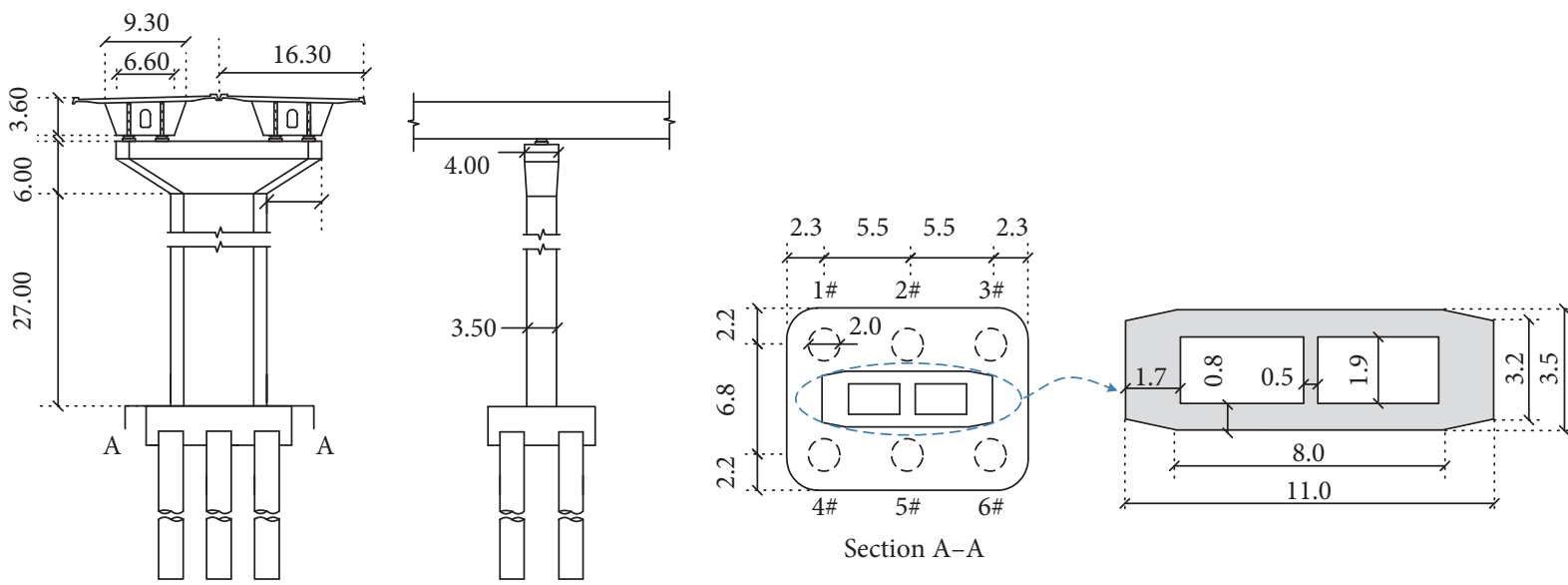

(b)

Figure 1: Schematic diagram of bridge and the main sections (unit: $\mathrm{m}$ ): (a) elevation view and (b) schematic diagram of component dimensions.

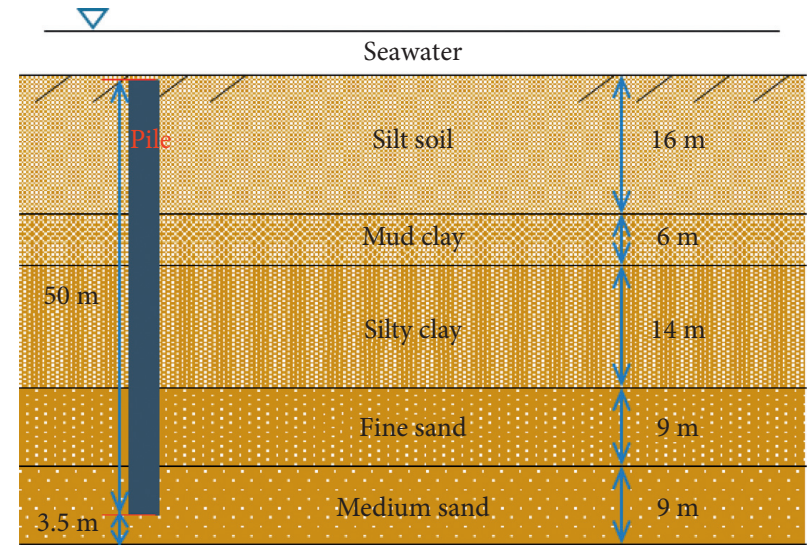

FIGURE 2: Schematic diagram of the soil layers.

TABLE 1: Main parameters of soil layers.

\begin{tabular}{lccccc}
\hline Soil layer & Soil type & Effective heavy $\left(\mathrm{kN} / \mathrm{m}^{3}\right)$ & Shear wave velocity $(\mathrm{m} / \mathrm{s})$ & Frictional angle $\left(^{\circ}\right)$ & Undrained shear strength $(\mathrm{kPa})$ \\
\hline Silt soil & & 9.4 & 80 & - & 9 \\
Mud clay & Clay & 12.2 & 110 & - & 21 \\
Silty clay & & 12.8 & 210 & 32 & 28 \\
Fine sand & \multirow{2}{*}{ Sand } & 14.0 & 250 & 36 & - \\
Medium sand & & 16.0 & 340 & - \\
\hline
\end{tabular}

$\left(R e_{p}\right)$ of the case. The response discrepancy rate for Case- $i$ and Case- $j$ is defined as $\left(R e_{p}\right.$ of Case- $i-R e_{p}$ of Case- $\left.j\right) /\left(R e_{p}\right.$ of Case- $j$ ). If the rate is positive, it means the response of Case- $i$ is larger than that of Case- $j$; if the rate is negative, it means the response of Case- $i$ is smaller. The discrepancy rates for Case 2 and Case 1 are shown in Table 4. Due to the symmetry 


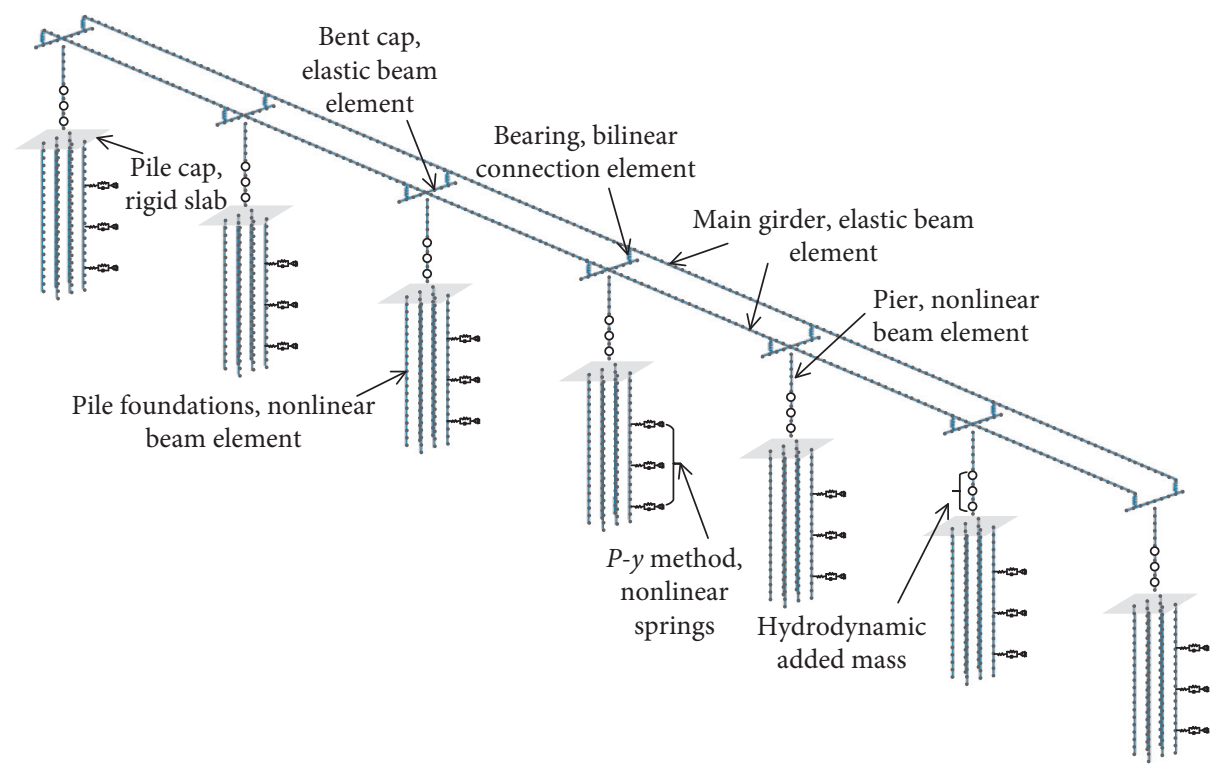

FIgURE 3: Finite element model of the example.
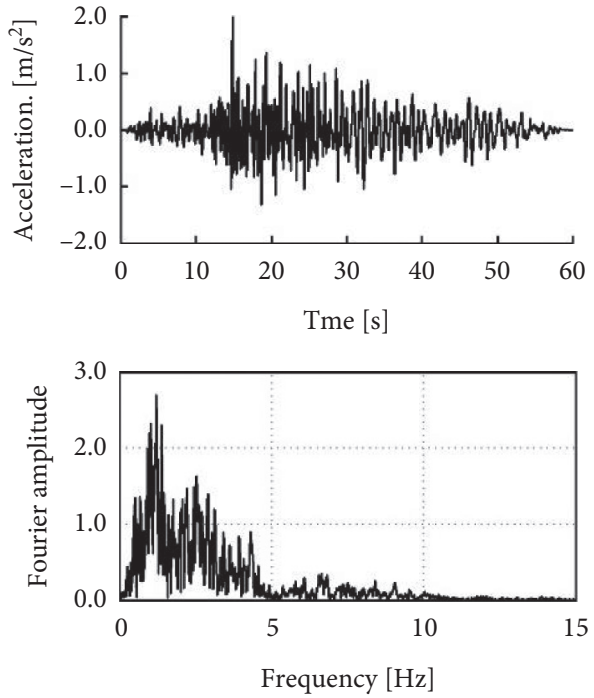

FIGURE 4: Ground motion acceleration of Chuetsu-oki and its Fourier amplitude spectrum.

of the structure, the rates of pier Nos. 1 and 5, pier Nos. 2 and 6 , and pier Nos. 3 and 7 are similar, so only the rates of pier Nos. 1 to 4 are listed in the table. The discrepancy rates of displacement and bending moment are both within 5\%, and the rates of bending moment are slightly less than those of displacement.

By comparing the responses of Case 3 and Case 4 in Table 2, the influence of water-structure interaction is obtained when pile-soil interaction is considered. According to Table 3, the elongation ratio of hydrodynamic force to the fundamental period is $1.6 \%$, which is slightly lower than that when pile-soil interaction is ignored.

Figure 7 shows the envelopes of relative displacement of pier Nos. 1 and 4, and Figure 8 shows the displacement of corresponding pile No. 1. The pile foundation numbers are shown in Figure 1. As can be seen, the hydrodynamic force slightly reduces the deformation of the piers along the whole height, while moderately increases the deformation of the piles. The response discrepancy rates for Case 4 and Case 3 are listed in Table 5. It can be seen that the reduction effect of water-structure interaction on pier deformation is within $5 \%$; meanwhile the enlargement effect on pile is in a range of $7 \% \sim 14 \%$.

Figure 9 shows the envelopes of bending moment of pier Nos. 1 and 4, and Figure 10 shows the bending moment of corresponding pile No. 1 . As can be seen, the hydrodynamic force changed the response of piers and piles which may increase or decrease in the height range of the components. Combined with Table 5, the change rates of piers are all positive and within 5\%; that of pile foundation could be positive or negative, and the absolute value is less than $10 \%$.

By comparing the responses of displacement and bending moment, it can be found that the influence of hydrodynamic force on displacement is greater than that of bending moment. By comparing the responses of bridge pier and pile foundation, it can be found that the effects of waterstructure interaction on the two are not consistent; that is, hydrodynamic force may increase the responses of piles while decreasing the responses of piers, and the opposite is also true. However, the influence on pile response is greater in the degree than that of bridge pier. Through the above two comparisons, it is apparent that, considering pile-soil interaction, the influence of hydrodynamic force on bridge response is greater.

4.2. Influence of Pile-Soil Interaction. Based on the responses of Case 1 and Case 3, the influence of pile-soil interaction without water surrounded is studied. Figure 11 is the time history of bending moment at the bottom of pier No. 4. It can be seen that pile-soil interaction significantly changed the bending moment response of the structure. And the 
TABLE 2: Cases analyzed.

\begin{tabular}{lcc}
\hline Case number & Depth of water $(\mathrm{m})$ & Pile-soil interaction \\
\hline 1 & 0.0 & None \\
2 & 20.0 & None \\
3 & 0.0 & Being \\
4 & 20.0 & Being \\
\hline
\end{tabular}

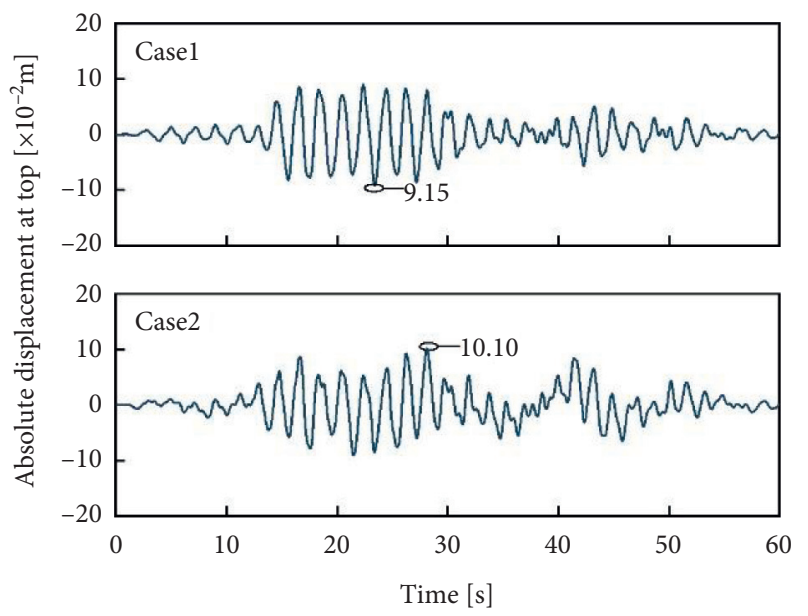

Figure 5: Absolute displacement time histories of pier No. 4 in Cases 1 and 2.

TABLE 3: Fundamental periods and the elongation ratios.

\begin{tabular}{lcccc}
\hline Item & Case 1 & Case 2 & Case 3 & Case 4 \\
\hline Fundamental period (s) & 1.71 & 1.74 & 3.18 & 3.23 \\
Change rate $(\%)$ & - & 1.8 (relative to Case 1) & 86.0 (relative to Case 1) & 1.6 (relative to Case 3) \\
\hline
\end{tabular}

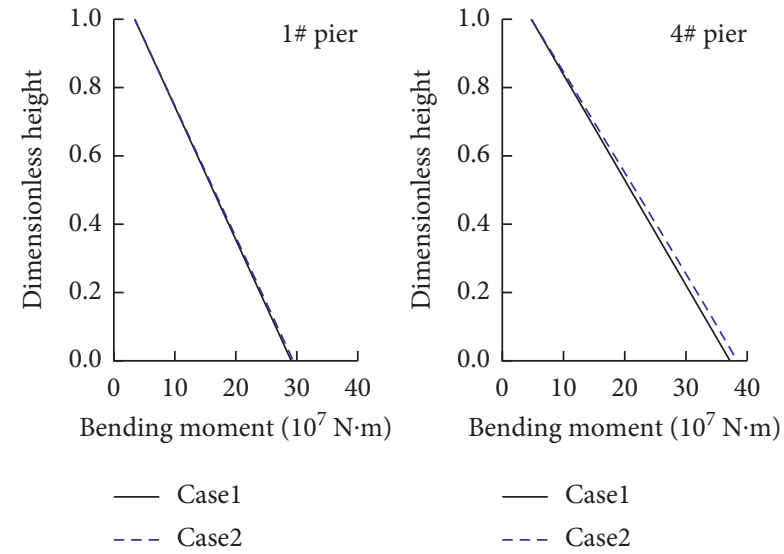

FIgURE 6: Bending moment envelopes of piers in Cases 1 and 2.

periodic characteristics, the amplitude, and time of the peak response are all changed dramatically: the period increases while the peak value decreases significantly. Combining with Table 3, the elongation ratio of pile-soil interaction to the fundamental period is $86 \%$.

Figure 12 shows the deformation envelopes of pier Nos. 1 and 4 relative to bottom of respective pier. It can be observed that there are some differences in the displacement distribution of the piers in the two cases. The displacement distribution of Case 1 is closer to the first-order mode shape, while that of Case 3 is partly closer to a line distribution. The response discrepancy rates for Case 3 and Case 1 are listed in Table 6. It can be seen that pile-soil interaction significantly reduces the peak response values of deformation and bending moment of bridge pier, and the absolute values of discrepancy rates of displacement are less than $30 \%$, while those of the bending moment are nearly $70 \%$.

According to the displacement time histories of the main girder relative to the pier top, as shown in Figure 13, it appears that the peak response of Case 3 is slightly smaller than that of Case 1, and the vibration periods are significantly different. It seems pile-soil interaction slightly reduces the relative displacement response of the main girder.

Based on the response of Case 2 and Case 4, the influence of pile-soil interaction with the consideration of hydrodynamic force is analyzed. The envelopes of bending moment under earthquake are drawn in Figure 14. Apparently, pilesoil interaction still significantly changes the response of the piers. Furthermore, the response discrepancy rates for Case 4 and Case 2 are listed in Table 7. The reduction rates of deformation and bending moment are as high as 35\% and $67 \%$, respectively. Combined with Table 6 , it is recognized that hydrodynamic force moderately intensified the reduction effect of pile-soil interaction, and the influence on displacement is more obvious. 
TABLE 4: Response discrepancy rates for Case 1 and Case 2 (\%).

\begin{tabular}{lllll}
\hline Rate & $1 \#$ & $2 \#$ & $3 \#$ & $4 \#$ \\
\hline Displacement & 1.3 & 2.4 & 2.8 & 3.4 \\
Bending moment & 1.4 & 2.2 & 2.7 & 3.0 \\
\hline
\end{tabular}
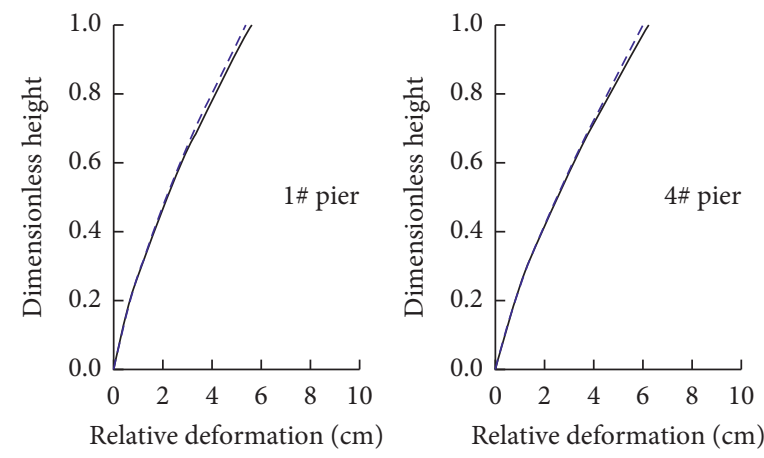

$$
\begin{array}{cc}
\text { - Case3 } & \text { - Case3 } \\
--- \text { Case4 } & \text { - }
\end{array}
$$

Figure 7: Displacement envelopes of piers in Cases 3 and 4.

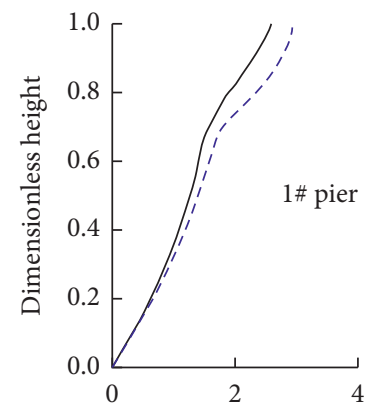

Relative deformation $(\mathrm{cm})$

$$
\begin{array}{r}
\text { - Case3 } \\
\text { - - C Case4 }
\end{array}
$$

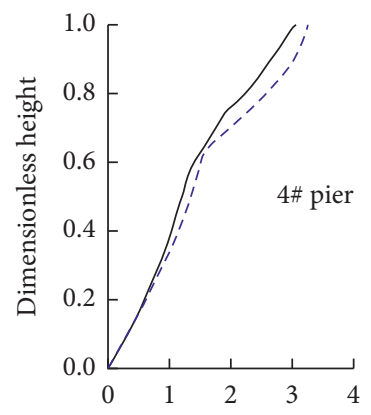

Relative deformation $(\mathrm{cm})$

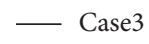

\begin{tabular}{|c|c|c|c|c|c|}
\hline \multicolumn{2}{|c|}{ Item } & $1 \#$ & $2 \#$ & $3 \#$ & $4 \#$ \\
\hline \multirow{2}{*}{ Pier } & Displacement & -4.6 & -4.2 & -3.9 & -3.7 \\
\hline & Bending moment & 2.8 & 2.9 & 3.1 & 3.0 \\
\hline \multirow{2}{*}{ Pile } & Displacement & 13.1 & 11.2 & 11.0 & 7.3 \\
\hline & Bending moment & 2.7 & -3.0 & 3.9 & -8.4 \\
\hline
\end{tabular}

- - Case4

Figure 8: Displacement envelopes of pile No. 1 in Cases 3 and 4.

TABle 5: Response difference rates for Case 3 and Case 4 (\%).

The above results suggest that the pile-soil interaction significantly changes the seismic response of the bridge: the vibration period of the structure is significantly prolonged; the maximum values of the pier displacement and bending moment are significantly reduced, and the change of bending moment is more prominent than the displacement. While the influence on the peak value of relative displacement of the girder is limited, the reason may be related to the use of LRB. When water-structure interaction is ignored, the influence of pile-soil interaction will be underestimated, especially for structural deformation.

Both the hydrodynamic force and pile-soil interaction prolong the period of structural vibration, and the pile-soil interaction has much greater influence. When the soilstructure interaction is neglected, water-structure interaction will increase the structure response; when soil-structure interaction is considered, the influence of hydrodynamic force is complex. From the perspective of pile-soil interaction, hydrodynamic force may increase the influence. 


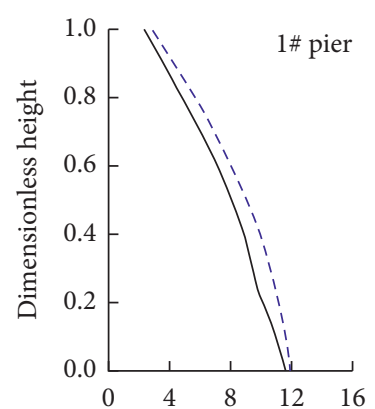

Bending moment $\left(10^{7} \mathrm{~N} \cdot \mathrm{m}\right)$

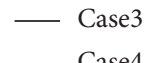

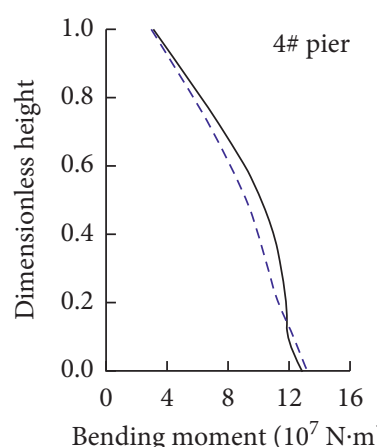

- Case3

Figure 9: Bending moment envelopes of pier No. 4 in Cases 3 and 4.
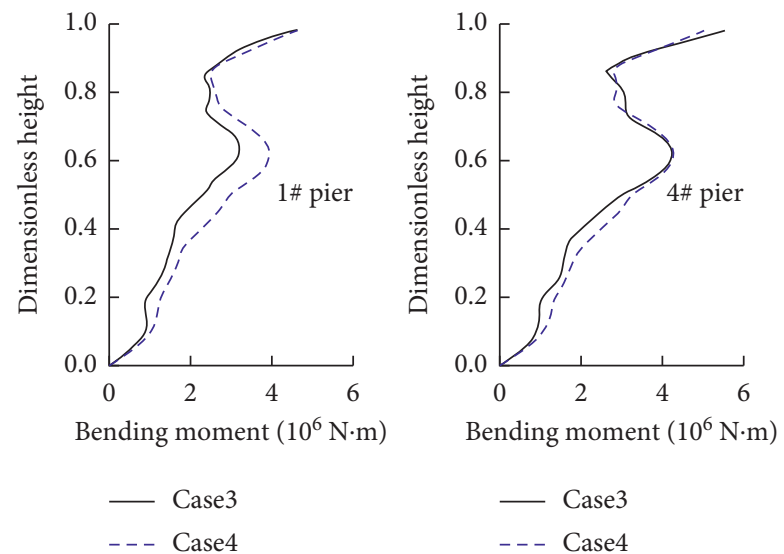

- Case3

- - - Case4

Figure 10: Bending moment envelopes of pile No. 1 in Cases 3 and 4 .

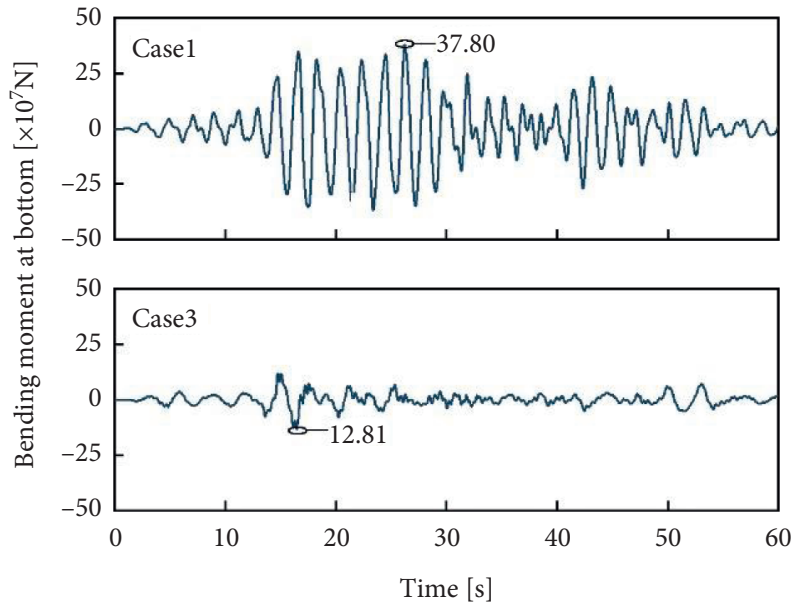

FIgURE 11: Bending moment time histories of pier No. 4 in Cases 1 and 3. 


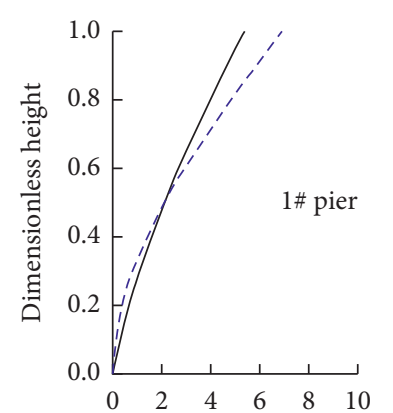

Relative deformation $(\mathrm{cm})$

--- Case 1

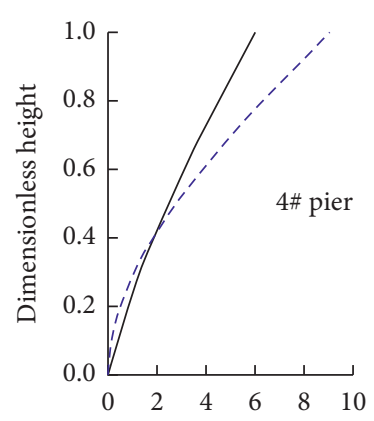

Relative deformation $(\mathrm{cm})$

- - Case1

_ Case 3

FIgURE 12: Displacement envelopes of piers in Cases 1 and 3.

Table 6: Response difference rates for Case 1 and Case 3 (\%).

\begin{tabular}{|c|c|c|c|c|}
\hline Item & $1 \#$ & $2 \#$ & $3 \#$ & $4 \#$ \\
\hline Displacement & -17.8 & -22.7 & -24.3 & -29.4 \\
\hline Bending moment & -59.1 & -62.9 & -63.2 & -66.1 \\
\hline
\end{tabular}

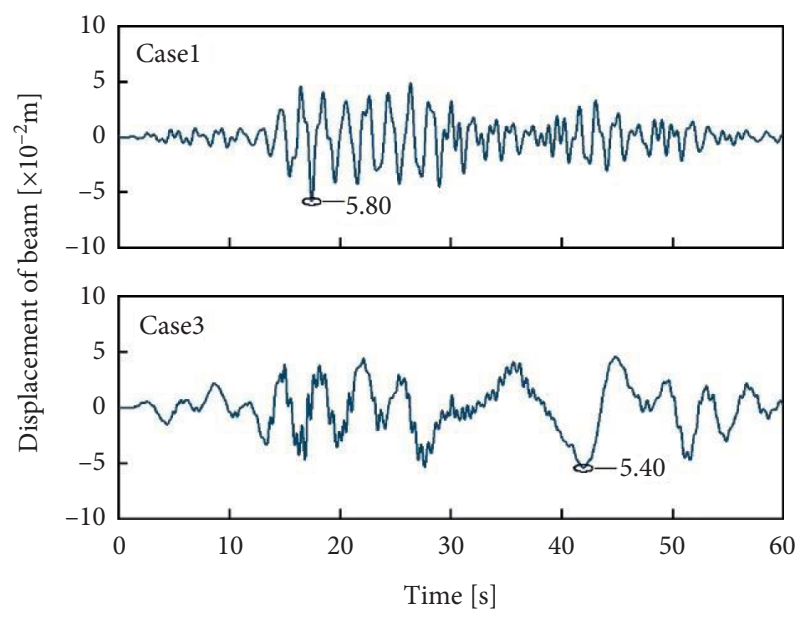

Figure 13: Displacement time histories of beam relative to pier No. 4 in Cases 1 and 3.
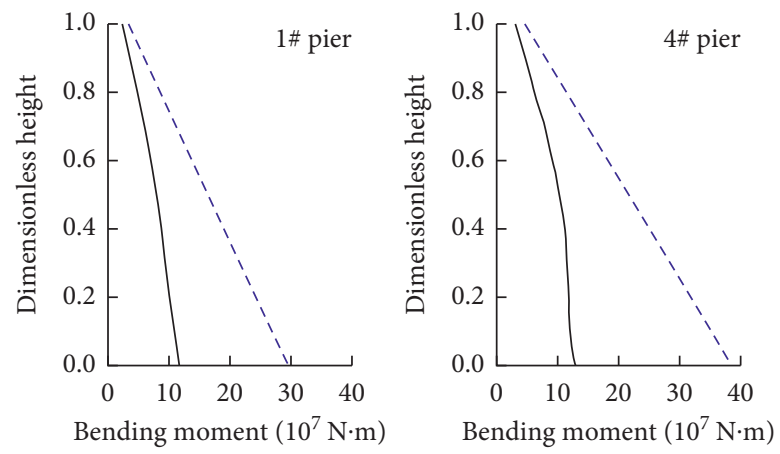

Bending moment $\left(10^{7} \mathrm{~N} \cdot \mathrm{m}\right)$

Bending moment $\left(10^{7} \mathrm{~N} \cdot \mathrm{m}\right)$

$$
\begin{array}{rr}
-- \text { Case2 } & -- \text { Case2 } \\
- \text { Case4 } & - \text { Case4 }
\end{array}
$$

FIgURE 14: Bending moment envelopes of piers in Cases 2 and 4. 
TABLE 7: Response difference rates for Case 2 and Case 4 (\%).

\begin{tabular}{lcccc}
\hline Rate & $1 \#$ & $2 \#$ & $3 \#$ & $4 \#$ \\
\hline Displacement & -22.7 & -23.0 & -26.6 & -34.3 \\
Bending moment & -60.7 & -59.3 & -62.2 & -66.5 \\
\hline
\end{tabular}

\section{Conclusions}

This paper presents a study on the dynamic response of seacrossing continuous girder bridge. By comparing the numerical results obtained from different cases, the influences of water-structure interaction and pile-soil interaction are preliminary investigated and discussed. The main conclusions are drawn.

The vibration periods and dynamic responses of the structure are slightly affected by water-structure interaction. This effect could be increased when pile-soil interaction is considered simultaneously. Compared with the pier, the influence of hydrodynamic force on pile is more significant. Compared with the bending moment, the displacement response is more influenced.

The vibration periods and dynamic responses of the structure are severely affected by pile-soil interaction. The vibration periods are obviously prolonged. The responses of deformation and force are reduced, and the bending moment is more affected than the displacement. The usage of isolation bearings may lead to slight impact on main girder.

The influence of pile-soil interaction is much more significant than that of hydrodynamic force. Meanwhile, the effect of coaction of the two is not a simple superposition of action alone, so the seismic analysis of such bridge should consider both effects.

The pile-soil interaction has obvious reducing effect in this study. Combined with the existing research, the pile-soil interaction may magnify the seismic response of structure. Therefore, the influence of pile-soil interaction is complex, and the effect cannot be generalized.

It should be noted that the difference of ground motion intensity, near-field earthquake, and vertical seismic excitation are not considered in this paper. As the notable influences of these factors have been proved for on-land bridge, they will be considered in the subsequent studies on the seismic responses of the offshore bridge.

\section{Data Availability}

All the raw data used to support the findings of this study are included within the article. All the raw data are available from the corresponding author upon request.

\section{Conflicts of Interest}

The authors declare that they have no conflicts of interest.

\section{Acknowledgments}

This work was supported by the National Natural Science Foundations of China (Grant no. 52178101) and the Open Project of Key Laboratory of Urban Security and Disaster
Engineering of Beijing University of Technology (Grant no. 2020B05). The support is gratefully acknowledged.

\section{References}

[1] M. A. Gutscher, J. Malavieille, S. Lallemand, and J. Y. Collot, "Tectonic segmentation of the north andean margin: impact of the carnegie ridge collision," Earth and Planetary Science Letters, vol. 168, no. 3, pp. 255-270, 1999.

[2] C. Zhang, C. Wu, and P. Wang, "Seismic fragility analysis of bridge group pile foundations considering fluid-pile-soil interaction," Shock and Vibration, vol. 2020, Article ID 8838813, 17 pages, 2020.

[3] J. Zhang, K. Wei, and J. Qin, "Resilience and economic loss assessment of highway bridges in deep reservoir under nearfault ground motions," Journal of Bridge Engineering, vol. 26, no. 3, 2021 .

[4] R. S. Jangid, "Seismic response of isolated bridges," Journal of Bridge Engineering, vol. 9, no. 2, pp. 156-166, 2004.

[5] J. Yi Meng and E. M. Lui, "Seismic analysis and assessment of a skew highway bridge," Engineering Structures, vol. 22, no. 11, pp. 1433-1452, 2000.

[6] M. Dicleli, "Seismic design of lifeline bridge using hybrid seismic isolation," Journal of Bridge Engineering, vol. 7, no. 2, pp. 94-103, 2002.

[7] M. Mallick and P. Raychowdhury, "Seismic analysis of highway skew bridges with nonlinear soil-pile interaction," Transportation Geotechnics, vol. 3, no. 3, pp. 36-47, 2015.

[8] C. C. Spyrakos, "Seismic behavior of bridge piers including soil-structure interaction," Computers \& Structures, vol. 43, no. 2, pp. 373-384, 1992.

[9] L. Di Sarno, F. Da Porto, G. Guerrini, P. M. Calvi, G. Camata, and A. Prota, "Seismic performance of bridges during the 2016 central Italy earthquakes," Bulletin of Earthquake Engineering, vol. 17, no. 10, pp. 5729-5761, 2019.

[10] Q. Han, X. Du, J. Liu, Z. Li, L. Li, and J. Zhao, "Seismic damage of highway bridges during the 2008 Wenchuan earthquake," Earthquake Engineering and Engineering Vibration, vol. 8, no. 2, pp. 263-273, 2009.

[11] N. Makris, D. Badoni, E. Delis, and G. Gazetas, "Prediction of observed bridge response with soil-pile-structure interaction," Journal of Structural Engineering, vol. 120, no. 10, pp. 29923011, 1994.

[12] T. C. Hutchinson, Y. H. Chai, R. W. Boulanger, and I. M. Idriss, "Inelastic seismic response of extended pile-shaftsupported bridge structures," Earthquake Spectra, vol. 20, no. 4, pp. 1057-1080, 2004.

[13] B. B. Soneji and R. S. Jangid, "Influence of soil-structure interaction on the response of seismically isolated cablestayed bridge," Soil Dynamics and Earthquake Engineering, vol. 28, no. 4, pp. 245-257, 2008.

[14] L. Chen, L. Jiang, L. Tao, and Z. Yu, "Seismic response analysis of high-speed vehicle-bridge considering soil-structure interaction," Rock and Soil Mechanics, vol. 33, no. 10, pp. 3162-3170, 2012.

[15] P. Wang, P. Long, M. Zhao, C. Zhang, and X. Du, "Analytical solution of earthquake-induced hydrodynamic pressure on arrays of circular cylinders considering high-order scattered waves," Journal of Engineering Mechanics, vol. 147, no. 9, 2021.

[16] A. Løkke and A. K. Chopra, "Direct finite element method for nonlinear analysis of semi-unbounded dam-water-foundation rock systems," Earthquake Engineering \& Structural Dynamics, vol. 46, no. 8, pp. 1267-1285, 2017. 
[17] W. Yang and Q. Li, "The expanded Morison equation considering inner and outer water hydrodynamic pressure of hollow piers," Ocean Engineering, vol. 69, pp. 79-87, 2013.

[18] W. L. Yang, Q. Li, and H. Yeh, "Calculation method of hydrodynamic forces on circular piers during earthquakes," Journal of Bridge Engineering, vol. 22, no. 11, Article ID 04017093, 2017.

[19] C.-Y. Liaw and A. K. Chopra, "Dynamics of towers surrounded by water," Earthquake Engineering \& Structural Dynamics, vol. 3, no. 1, pp. 33-49, 1974.

[20] J. Guo, M. Zhao, P. Wang, and N. Zhang, "Comparative assessment of simplified methods for hydrodynamic force on cylinder under earthquakes," Ocean Engineering, vol. 234, Article ID 109219, 2021.

[21] X. Du, P. Wang, and M. Zhao, "Simplified formula of hydrodynamic pressure on circular bridge piers in the time domain," Ocean Engineering, vol. 85, pp. 44-53, 2014.

[22] M. Greenhow and L. Yanbao, "Added masses for circular cylinders near or penetrating fluid boundaries-review, extension and application to water-entry, -exit and slamming," Ocean Engineering, vol. 14, no. 4, pp. 325-348, 1987.

[23] Q. Li and W. Yang, "An improved method of hydrodynamic pressure calculation for circular hollow piers in deep water under earthquake," Ocean Engineering, vol. 72, pp. 241-256, 2013.

[24] H. Jiang, B. X. Wang, X. Y. Bai, C. Zeng, and H. D. Zhang, "Simplified expression of hydrodynamic pressure on deepwater cylindrical bridge piers during earthquakes," Journal of Bridge Engineering, vol. 22, no. 6, Article ID 04017014, 2017.

[25] P. Wang, M. Zhao, X. Du, J. Liu, and J. Chen, "Simplified evaluation of earthquake-induced hydrodynamic pressure on circular tapered cylinders surrounded by water," Ocean Engineering, vol. 164, pp. 105-113, 2018.

[26] M. Zhao, Y. Huang, and P. Wang, "Simplified model for the earthquake induced hydrodynamic pressure on rectangular cylinder," Journal of Beijing University of Technology, vol. 45, no. 12, pp. 1212-1217, 2019.

[27] X. Huang and Z. X. Li, "Influence of hydrodynamic pressure on seismic response of bridge piers in deepwater," China Civil Engineering Journal, vol. 44, no. 1, pp. 65-73, 2011.

[28] W. P. Wu, S. S. Liang, P. Liang, and S. G. Long, "Journal of disaster prevention and mitigation engineering influence of hydrodynamic pressure and pile-soil interaction (PSI) on seismic performance of high pier bridges in deep water," Journal of Disaster Prevention and Mitigation Engineering, vol. 41, no. 1, pp. 67-74, 2021.

[29] Y. Deng, Q. Guo, Y. I. Shah, L. Xu, and F. Paolacci, "Study on modal dynamic response and hydrodynamic added mass of water-surrounded hollow bridge pier with pile foundation," Advances in Civil Engineering, vol. 2019, Article ID 1562753, 23 pages, 2019.

[30] M. B. Adeel, M. A. Jan, M. Aaqib, and D. Park, "Development of simulation based p-multipliers for laterally loaded pile groups in granular soil using 3D nonlinear finite element model," Applied Sciences, vol. 11, no. 1, p. 26, 2021.

[31] S. Carbonari, F. Dezi, and G. Leoni, "Seismic soil-structure interaction in multi-span bridges: application to a railway bridge," Earthquake Engineering \& Structural Dynamics, vol. 40, no. 11, pp. 1219-1239, 2011.

[32] Q. Han, J. Wen, X. Du, Z. Zhong, and H. Hao, "Nonlinear seismic response of a base isolated single pylon cable-stayed bridge," Engineering Structures, vol. 175, pp. 806-821, 2018.

[33] H. Matlock, "Correlations for design of laterally loaded piles in soft clay," pp. 77-94, 1970, Offshore technology in civil engineering's hall of fame papers from the early yearsOTC1204-MS.

[34] Recommended Practice for Planning, Designing and Constructing Fixed Offshore Platforms-Working Stress Design, American Petroleum Institute (API), Washington, DC, USA, 20th ed. edition, 1993.

[35] Y. Bin, Study on Simplified Models of Bridge Pile-Foundation Subjected to EarthquakeTongji University, Shanghai, China, 2007.

[36] X. J. Duan, A Soil Structure -Interaction Analysis of Tall Buildings, University of Southern California, Los Angeles, CF, USA, 1999.

[37] O. Maeso, J. J. Aznárez, and F. Garcia, "Dynamic impedances of piles and groups of piles in saturated soils," Computers \& Structures, vol. 83, no. 10-11, pp. 769-782, 2005.

[38] D. A. Brown, L. C. Reese, and M. W. O'Neill, "Cyclic lateral loading of a large-scale pile group," Journal of Geotechnical Engineering, vol. 113, no. 11, pp. 1326-1343, 1987.

[39] D. A. Brown, C. Morrison, and L. C. Reese, "Lateral load behavior of pile group in sand," Journal of Geotechnical Engineering, vol. 114, no. 11, pp. 1261-1276, 1988.

[40] Gb50017-2017, Standard for Design of Steel StructuresMinistry of Housing and Urban-Rural Development of the People's Republic of China, Beijing, China, 2017.

[41] GB 50010-2010, Code for Design of concrete Structures Ministry of Housing and Urban-Rural Development of the People's Republic of China, Beijing, China, 2015.

[42] PEER, Pacific Earthquake Engineering Research center Ground Motion Database-Ngawest2, Pacific Earthquake Engineering Research. (PEER), Berkeley, CF, USA, 2013, http://ngawest2. berkeley.edu/. 